\title{
Ellipsis: History and Prospects
}

\author{
E.P. BRANDON University of The West Indies
}

This paper is intended to bring the notion of ellipsis to the conscious attention of philosophers. I expose the notion to the light because I believe it is a fruitful one, especially for informal logic.

It is curious that in the thousands of years in which philosophers have had access to, and have used, the notion of ellipsis no one has, as far as I know, given it an account, explication, theory, criteria for recognition, or any of the other desiderata for terms of art in philosophical logic.[1] In fact those authors who make use of the term rarely offer anything by way of explaining or justifying what they are doing. It would seem that the notion is employed as a piece of obvious common-sense that can be invoked when necessary, an unproblematic borrowing or adaptation of a traditional notion in grammatical or stylistic studies. Perhaps this location in another specialty may help to account for philosophical insouciance, though in the twentieth century at least one would not expect a philosopher to assume that he can borrow from traditional grammar in a logical discussion without even the slightest explanation or justification.

I intend to sketch the broad outlines of the use of ellipsis both in traditional grammar and in recent philosophy, and then to turn to its role for us now. The survey of other people's usage will necessarily be somewhat lengthy, but it should illustrate the fecundity of the notion.

\section{1}

The Greek etymon of 'ellipsis' (Latinized as detractio) was a part of the stock analytical vocabulary of rhetoric and was glossed as the omission of words that could be understood from the context. Thus Georgius Choeroboscus, a minor rhetorician, tells us that a Homeric phrase, kopton amphoterais (Od. 18, 28), literally 'striking with both', is elliptical for 'striking with both hands' (for this and other examples, see Lausberg, 1960, p. 346). And ellipsis was often invoked by Greek and Latin writers to account for syntactic structures that appeared incomplete, such as subject-predicate sentences without a copula.

Omissions that can be understood constitute a fairly mixed bunch, with imprecise boundaries. These difficulties with the notion are clearly revealed, for instance, in Quintilian's Institutes. He notes that other writers classify ellipsis with synecdochepart for whole or whole for part-(VIII. vi. 21) or with aposiopesis - the breaking off of a sentence in mid-stream(IX. iii. 60) but for him ellipsis is a more regular phenomenon 'where the word omitted may be clearly gathered from the context'.[2] He offers an example of the historic infinitive which was supposed to require a finite verb, and he also claims that obvious omissions of indelicate expressions can be subsumed under the same concept. As a sub-species, he notes cases of syntac- 
tic yoking together such as the Ciceronian 'lust conquered shame, boldness fear, madness reason'. [3]

Jumping two thousand years, we can find the same types of case and the same uncertainties about ellipsis in a recent generation of grammarians. Jespersen may serve as an example, both of a strict tradition in grammatical analysis and of a bridge to the conception of ellipsis used by philosophers.

With respect to the first point, Jespersen is sharply critical of what he considered abuses of the idea of ellipsis to defend preconceived notions of grammatical structure against obviously normal sentences that fail to conform. Thus in a long footnote he attacks Sweet's account of sentences such as (1):

\section{(1) What you say is true.}

Sweet had claimed that the word 'what' was doing duty here for two words, one the object of 'say', the other the subject of 'is'. Jespersen objects that the subject of 'is true' cannot be 'what' (nor presumably any other word hidden within it)[4] but only the whole clause 'what you say'. He rejects this 'kind of pseudo-grammatical analysis ... one of the numerous uncalled-for fictions which have vitiated and complicated grammar without contributing to a real understanding of the facts of language' (1924, pp. 103-4). He does, however, concede a place for ellipsis, but only where ... absolutely necessary, and where there can be no doubt as to what is understood' (p. 307). One of his examples of genuine ellipsis is (2):

(2) He is rich, but his brother is not $/ /$.

Elsewhere he allows that answers and retorts permit (indeed often all but require) words or phrases to stand alone that otherwise could not do so. Both these kinds of ellipsis continue to feature in popular guide books (e.g. Fowler, 1983) and in standard transformational grammars. [5]

Another traditional kind of example that deserves separate mention is provided by the semantics of some words or phrases, usually nominal. Thus Ullmann mentions the preceding cases of ellipsis but concentrates on examples such as 'a daily' meaning a daily newspaper, or the doubly elliptical and apparently aberrant 'un première de Lyon' which abbreviates 'un billet de première classe de Lyon' (1962, pp. 222-3). $\mathrm{He}$ also notes the strong tendency for such things to happen among specialized groups-lawyers will understand 'action' as a legal action, students will interpret 'a paper' as an examination paper, and so on (pp. 161-2).

These three rough groups-responses, some compressed structures, abbreviated phrases - seem to exhaust acceptable examples of ellipsis for much traditional grammar, and I shall lump them together under the label 'grammatical ellipsis'. They do not include the forced attempts to save preconceptions such as Jespersen attacked, and they keep close to his admonition to be in no doubt about what has been elided. They are also in large part based on syntactic considerations. [6] I want to group these cases together because 1 intend to contrast them with other cases that Jespersen also mentions and that have, I believe, much more in common with the philosophical appropriation of the notion that I shall sketch below. These other cases are semantically inspired and appeal to what I hope are intuitively 'deeper' considerations than the grammatical ellipses.

The first group are something of a bridge between grammatical ellipsis and the philosophers' kind-they arise from semantic reflection on syntax of the sort typical of transformationalist 'deep' structure, and in fact Jespersen's examples seem to belong among Allerton's (1975) 'obligatory deletions'. After noting some of the cases of simple grammatical ellipsis allowed in dialogue where only one of the two notions joined in what he calls a 'nexus' is expressly mentioned, Jespersen goes on to apply the same analysis to 'the great majority of cases in which we use either an infinitive or a nexus-substan-

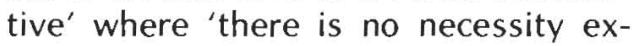


pressly to indicate who or what is the subject of the nexus' (1924, p. 143). Thus he claims that in (3):

\section{(3) I like to travel.}

an ' $I$ ' must be understood as subject of the verb 'to travel'. After all, I'm not claiming to like the fact that people travel; I like my travelling. In (4):

\section{(4) To travel is easy nowadays.}

he says that the 'generic person' is understood: for one to travel is easy nowadays. Jespersen offers some evidence for the unexpressed existence of such items, but without entering into these grammatical arguments, I think we can see that fundamentally this sort of ellipsis is semantically motivated. But in these cases there need be no simple way in which the elided elements can be inserted into the surface structure, though (5) is perhaps not very ungrammatical:

\section{(5) *I like me to travel.}

Invoking elided subjects for subjectless infinitive verbs might seem dangerously close to the evasions Jespersen had condemned in others, but what he forbids in criticism of ellipsis he gives back in much more generous measure in his concluding remarks on 'suppression'. Leaving aside detailed grammatical analysis for some general remarks about how we convey meaning in speech and writing, he says:

In all speech activity there are three things to be distinguished, expression, suppression, and impression. Expression is what the speaker gives, suppression is what he does not give, though he might have given it, and impression is what the hearer receives.... Suggestion is impression through suppression. Only bores want to express everything, but even bores find it impossible to express everything. Not only is the writer's art rightly said to consist largely in knowing what to leave in the inkstand, but in the most everyday remarks we suppress a great many things which it would be pedantic to say expressly.... Compound nouns state two terms, but say nothing of the way the relation between them is to be understood....
As in the structure of compounds, so also in the structure of sentences much is left to the sympathetic imagination of the hearer, and what from the point of view of the trained thinker, or the pedantic schoolmaster, is only part of an utterance, is frequently the only thing said, and the only thing required to make the meaning clear to the hearer. (p. 309)

Here we have a classic expression of what I shall call 'semantic ellipsis', the kind that philosophers have appropriated. But it is noteworthy that like most appeals to the importance of context it fails to specify how such omissions are to be restored or how our grasp of such sketchy sentences is to be understood. Jespersen's remarks come after all the detailed work has been done; they remind us of the vast background that work has ignored, but they leave it as obvious and not to be analyzed.

From one perspective, the idea of ellipsis, or Jespersen's suppression, could be seen as imbuing virtually all philosophy or logic. As Altham remarks, many have thought that a central task for logic is to make 'explicit what is implicit in informal usage' (1971, p. 77), and philosophers continually seek to make the hidden visible, to reveal apparent qualities as really relations, to uncover what we are implicitly committed to, and in many other ways to fill in some of the complexity we either leave to each other's sympathetic imaginations or are ourselves unable normally to conceive. But while my enquiry could easily flow into this trackless expanse, I think it worthwhile to ask what exactly those philosophers who have borrowed the terminology of ellipsis have made of it.

As noted above, philosophers seem not to treat ellipsis as a central concept to be explained or justified, but simply as something they can invoke when it suits them. There is apparently at least one tradition of recent philosophical writing in which ellipsis occurs as an 
opening gambit: the philosophy of probability. Ever since Keynes at least, writers have claimed that in some cases our use of the word 'probable' $^{\prime}$ is elliptical. Thus Keynes himself:

When in ordinary speech we name some opinion as probable without further qualification, the phrase is generally elliptical. We mean that it is probable when certain considerations, implicitly or explicitly present to our minds at the moment, are taken into account. We use the word for the sake of shortness, just as we speak of a place as being three miles distant, when we mean three miles distant from where we are then situated, or from some startingpoint to which we tacitly refer. (1921, p. 7)

A very similar doctrine was expounded by Kneale (1949, p. 10), only to be rejected by Toulmin (1956). More recently Ayer has also said that these ordinary judgments of probability, or what he calls 'credibility', are not to be understood in the Keynes-Kneale manner'they are not judgements about the evidence on which they are based' (1972, p. 58)-but he continues the tradition in his own way by remarking that 'judgements of probability, in the statistical sense, turn out to be elliptical' (p. 54).

Ayer's own account of what ordinary non-statistical probability judgments do mean seems not to arrive at any precise conclusion (pp. 58-61), but his position seems close to Mackie's view of what he calls 'simple probability' (the 'good reasons' end of informal probability):

One particularly tricky point is that simple probability is relative but not relational. The simple probability that I ought to assign to a proposition depends upon what information I have and what I have not: it is relative to my state of mixed knowledge and ignorance. In saying 'Probably $\mathbf{P}$ ' or 'It is $x \%$ probable that $\mathbf{P}$ ' or 'There is an $\mathbf{n}$ to 1 chance that $\mathbf{P}$ ' I am speaking from a certain point of view; but it is $\mathbf{P}$ itself that I am speaking about, not the relation between $\mathbf{P}$ and the knowledge-ignorance mixture that fixes this point of view.... The simple probability statement takes one's present state of knowledge and ignorance as setting the framework, as fixing the universe of possibilities under consideration. (1973, p. 173)

We shall return later to the significance of Mackie's distinction between relative and relational.

Keyne's analogy with distance indicates another branch of philosophy in which we can find explicit mention of ellipsis. Swinburne, for instance, argues that claims about distance assume a frame of reference, so that most talk of distance is elliptical in a deeper way than Keynes suggests. While Swinburne says that such a frame of reference need not be explicitly stated in most ordinary cases, because it is patently obvious which frame is being used, he invokes the notion of ellipsis when he considers a case in which it is not clear which frame of reference is in question - 'here indeed 'distance' is elliptical and we need explicit specification of the frame in which it is to be measured before we can say how far apart are the places' $(1968$, p. 80). It seems that Swinburne would say that (6):

\section{(6) $A$ is 10 metres from $B$}

is not elliptical when we all know which frame of reference is left unstated, but becomes elliptical when we do not. While this contrast is important, it does not seem helpful to make it in this way. Sentences such as (6) are elliptical (so Keynes' example is doubly elliptical) but in ordinary uses unambiguous and determinate, since we all know which frame is being suppressed. But when we do not know this, their ellipsis makes them ambiguous or indeterminate. Often, especially in criticism, it is only in the second sort of case that one wishes to insist on the ellipsis, but, as Swinburne's argument shows, important philosophical points can arise in the first sort of case too.

The awkwardness due to people's lack of anything definite in mind surfaces in two interestingly similar analyses of 'ought', Sloman (1970) and 
Wertheimer (1972). Sloman unhesitatingly invokes ellipsis and discovers in (7):

(7) It ought to be the case that $p$. the two elided elements restored in (8):

(8) Considering the possibilities in $Z, p$ ought to be the case relative to the basis, B.

Since he claims that sentences like (7) involve a choice among possibilities made on some basis, he asks how all this connects with what is going on in people's minds. Apart from 'considered attempts to say something true or false', his answer is that what people have in mind may be more or less unclear, but instructively he concludes that it is 'less important here to give a strictly accurate account of what people actually do say than to suggest what they might say if only they knew how' (1970, p. 394). While Wertheimer eschews the term 'ellipsis', I do not think there is any difference of substance between his kind of analysis of the verbal auxiliaries in terms of an understood 'System' and that offered by Sloman; and he too has to say how his understood System connects with ordinary people.[7] And similarly I would suggest that the kind of analysis of causal language that appeals to the notion of a causal field [8] can reasonably be construed along the lines of Sloman's outright use of ellipsis.

But to continue our sampling of philosophical uses of ellipsis, let us note a chapter in Platts' discussion of a Davidsonian theory of meaning, a chapter on adjectives (1979, ch. VII). Ellipsis is continually invoked, but with a sense of its lack of the appropriate rigour (it does not appear in the index):

Consider the sentences:

(9) Theo is large. [9]

and

(10) Rudy is attractive.

Until we know, or form beliefs about, the appropriate filling, we have no complete understanding of these sentences. We know (up to a point) the meanings of the words they contain, and (perhaps) their syntactic structure; but we have no idea which conditions would make the sentences true or false. This (vague) thought is what I mean by saying that (9) and (10) are elliptical. It also explains why 'thing' is a dummy filling, since such filling effects no change in the deficiency. (pp. 167-8)

Platts has given us to believe that Theo is a flea, and he later argues that if we try to understand (9) as involving a comparison between Theo and other fleas we still have an ellipsis of the respect(s) in which Theo is larger than the others (cf. p. 182ff). He also suggests that Rudy may be attractive to look at, to have dinner with, as a ballet-dancer, or what-have-you. I refrain from pursuing the fascinating issues Platts has raised, but it is worth entering a doubt about (10)-it is unspecific, but should we regard it as elliptical?

Platts' example confronts us with a problem that has bedevilled the notion of ellipsis since the Greeks: the relation of a useful notion of ellipsis to lack of specificity. We always leave some things unsaid, and often such details can easily be restored by a sympathetic hearer; should we then say that such details are elided? This problem has been viewed as a fundamental objection to the kind of elliptical analyses we have been examining. According to Hamblin's history of logical inattention to fallacy, Boethius noted that some grammatical contradictions were only apparent, because of the suppression of different relata, as for instance:

(11) Socrates is on the right-hand side $/ /$.

and

(12) Socrates is not on the right-hand side $/ /$.

Hamblin later suggests a formal treatment of this and other examples in terms of ellipsis, but rejects it in these words:

The odious feature of our formal theory, considered as a remedial device, is its insistence that what we have called 
'incomplete' predicates are deficient and need to be completed.... That there are certain respects in which it is unspecific is an essential characteristic of any utterance whatsoever. (1970, p. 212)

But this criticism is beside the point, for genuinely elliptical examples such as (11) and (12), if not for some of the other cases Hamblin considers. We need a distinction between truth, the whole truth, and the lack of sufficient detail to start enquiring about truth. Thus in the case of (11), we cannot begin to judge whether what it says is true until we have fixed the perspective (e.g., looking north from where Pericles is standing), but once that has been fixed its truth or falsity needs no more detail, although of course there is an unlimited amount of such detail that it omits-is Socrates standing or sitting, asleep or awake,.... As Platts says, and as Swinburne's example shows, there is a certain amount of vagueness about this contrast, but by no means enough to put it out of action.

This brief survey of what some philosophers have made of the notion of ellipsis shows, I hope, several things: their concept is an extension of the one found in traditional grammar and rhetoric; it tends to focus on what must be restored for there to be a determinately true or false proposition asserted; its users are not always clear about how this indeterminacy relates to a general lack of specificity; and there is a question how far the theory of ellipsis is intended to be a true description of linguistic behaviour and how far a normative replacement for it. But the range, and importance, of the examples also suggests that it would be salutary to clarify these issues and evaluate the contribution the notion of ellipsis can make to philosophical and logical enquiry.

I have suggested that the core idea of semantic ellipsis in philosophy is that in some, but by no means all, sentences certain items are left unspecified which are required in order for the sentence to be evaluated for truth or falsity. Ellipsis gives certain sentences a truth-value indeterminacy. But we must immediately distinguish this source of indeterminacy from the workings of proper names, token-reflexives, or non-designating referring expressions.

Any use of sentence (13):

(13) Ronald Reagan is walking.

requires us to supplement it with knowledge of which Ronald Reagan is in question and with knowledge of which extent of space-time is in question, but these ways in which the contributions of the context are mediated are well known and can be taken for granted here. Once they are given, (13) provides us with all we need to determine its truth on an occasion of utterance (leaving aside odd borderline forms of locomotion), though of course there is much that it leaves unsaid about the walking. But (14):

(14) Ronald Reagan needs to walk more / /.

still cannot be evaluated after we have deciphered the clues offered by proper names and occasion of utterance unless we know at least for what end or purpose he needs to walk more. For his health, it may not be true, but to stand a chance of winning the White House staff walking race it may well be (see my 1980 for a fuller discussion of the verb 'need').

It is worth noting here that one cannot resolve the ellipsis in (14) by appeal to some existentially quantified item$A$ needs $X$ for some $Y$ or other-since virtually all such claims would then be true. But we do not treat such claims in this way. Still, there are items that involve elided existential quantifications (e.g. 'is married') but I would suggest that they not be regarded as cases of semantic ellipsis; rather I would be inclined to put the implicit quantification into the meaning of the predicate. Similarly agent deletions with passives (e.g. 'John was murdered', 
given that Bill murdered John) and analogous transformational deletions are not to be regarded as semantic ellipses. But where the kind of quantificiation is left unspecified, I think we can usefully invoke ellipsis (see my 1982 for a discussion of 'truth is worth pursuing' in such terms). These cases, like example (10), reveal the imprecise boundaries of the conception of ellipsis I have adumbrated, but I think they suggest a need for collaborative effort rather than for a rejection of the whole approach.

Besides looking directly at how much must be restored for anything true or false to be in question, one can also follow Boethius, Sloman, and Wertheimer in using what appear to be logical irregularities as symptoms of ellipsis. Thus the fact that it might be true both that Mary can go to the office party (her car is back on the road) and that she can't (she has promised to babysit) suggests very strongly that there is more logical structure than meets the eye. In the spirit of the AndersonMackie causal fields mentioned earlier, one might suggest here that in using 'can' we elliptically invoke various 'obstacle fields' - as far as physical obstacles go, there is nothing to prevent Mary attending the party, but as far as moral obstacles go, there is one, since she has agreed to baby-sit. Boethius and I have offered examples of apparent contradictions; Sloman has a section looking at apparent failures of simple patterns of valid inference. The moral is the same: logical regularity can be restored by postulating elided structure, by specifying what Mackie might have called the 'logical cues' governing our normal use of language (1973, p. 7).

If an ellipsis is suspected, how is it to be restored? The rough question one is trying to answer is fairly clear: what else, over and above the workings of proper names and token-reflexives, do we need to know to begin to ascertain the truth value of the sentence in question? But is there any special way to answer it? The question of the methods of logical investigation seems not to have been much discussed. I am fairly sure we have no special roads to the truth here; I have elsewhere (1978) suggested an analogy with a Lakatosian research programme, but it was just a hint. So, unhelpfully, one can only say that the way to find the best characterization of talk of needs or spatial position is yet another process of conjecture and refutation, even if some of the conjectures are pretty obvious. Talk of left and right obviously has something to do with a perspective; it is not so clear whether it is the speaker's (which would generate a kind of tokenreflexivity) or a more variable frame of reference. Another way in which this answer is unhelpful, though true, is that the analyses it describes will depend on a vast amount of background knowledge about what is in fact required to determine truth or falsehood. We can see this in the contrast between Keynes' view of talk of distance and that advocated by Swinburne: in the light of relativity theory, we now see the need to specify a frame of reference to measure distance, so a hitherto unsuspected ellipsis is revealed in our use of language.[10]

If this characterization of ellipsis in philosophy is on the right lines, it may help to explain the disinclination to focus on the notion that 1 mentioned at the beginning. In cases of ellipsis people omit crucial components of a determinate meaning. Their words, the language they make publicly available, does not contain the whole story. Proper names and token-reflexivity are so pervasive that we do not usually worry overmuch about how accurately our theories of these phenomena capture the reality of language use and thought. In describing real language use we can hardly avoid noticing the phenomena I grouped together as grammatical ellipsis, but these are equally of little or no philosophical concern. The philosophically interesting cases are precisely those where the specification of elided elements is more speculative. But talk of ellipsis offers a fairly precise way of specifying the contributions usually sloughed off 
into context. It all but forces one to face the possibility, acknowledged, as we have seen, by both Sloman and Wertheimer, that many people have not in fact got any determinate meaning in mind. As Swinburne claims, we may all know which frame of reference is being elided in our normal talk of places and distances; but what are we agreeing to omit in talk àout equality or needs?

In such cases, it is very plausible to think that what many people mean is simply incomplete; they have no clear idea either of what they are saying or of what would be relevant criticism or support thereof. An accurate account of what is meant is almost beyond us. This is somewhat similar to Mackie's position on some probability statements People are ascribing a predicate to an opinion; it is relative in that its ascription can only be tested by reference to some body of evidence, as Keynes suggested, but the claim itself is not a relational claim, linking, either explicitly or implicitly, this opinion to the background of mixed knowledge and ignorance. What is consciously entertained is indeterminate, perhaps confused, an attempt to think a relational property as an intrinsic one.

Altham's alternatives, 'either attributive plurality assertions are inherently unclear, and have no determinate logic, or the predicates are implicitly

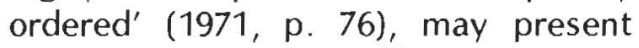
too extreme a contrast, but it captures the perplexity $i$ have been trying to suggest. If the contrast is appropriate, the only option for a philosopher or logician would seem to be to work with his explicit theory-one cannot do much with inherent unclarity and indeterminacy-so there would be little encouragement to spend much time on the failure of ordinary language to come up to scratch. But that is precisely what the notion of ellipsis does; it returns you to the ordinary language with the bland assurance that all will be well when a few holes have been filled in

A somewhat similar situation can be found in the failure of logicians to take the theorizing of fallacies seriously, a failure well argued by Hamblin (1970) and Johnson and Blair (1980). It is no doubt hard enough to get logic right without worrying overmuch about what exactly is going on when people get it wrong. Even closer to my topic is the similarly off-hand treatment meted out to enthymemes-suppressions of whole sentences rather than their components - and implicit assumptions generally (for which see Ennis, 1982).

Not only does ellipsis return our attention to what is, philosophically, a somewhat inadequate natural language, but as I have suggested, it does so in a very simple way. It supposes that an adequate semantic story can be told simply by inserting a few elements into what is already a grammatical sentence. But very many philosophical analyses can hardly be regimented in this way. Russell's theory of definite descriptions, or C.J.F. Williams' theory of truth (1976), which treat natural language sentences as existentially quantified conjunctions, change the whole shape of the natural language they analyse. When they invoke elements not visible on the ordinary language surface there need not be any obvious gap in which to insert them. Of course, over the centuries logicians have contorted natural languages in various ways, so it might be possible to provide an analysis in terms of ellipsis, but such an analysis might well not have the attractions of those we have been considering.

I have indicated some reasons the notion of ellipsis might seem uncongenial or inadequate to philosophers. Can we add anything in defence? I think at least two points can be made. The first is perhaps the less important, philosophically, though it might be more attractive to linguists and those philosophers currently trying to offer fragments of a theory of meaning for a natural language. Linguistic theory, at least since early Chomsky, has been plagued by its apparent power. Any number of very differently organized rule systems could, in principle, generate the observed sentences of a language. Of course, it is logically possible 
to have unlimited numbers of alternative theories that account for our data in any area; but for all its philosophical interest, this is hardly a live issue in most of the sciences. But linguistics has seemed less able to cope than these other areas. One reaction has been the rejection of the contrast of 'deep' and 'surface' structures (found, for instance, in Matthews, 1970, and Hudson, 1976) which would seem to require linguistic analyses to keep very close to what is actually said. In an associated semantic theory, it would not be surprising to find ellipses playing a major role:

In arguing that deletions have no place in syntax, I shall of course be implying that 'understood' elements are to be identified in the semantics, which seems the right place for them to be. (Hudson, 1976, p. 126)

But while ellipsis might still be a fruitful concept in linguistics, I think that, for philosophy and informal logic, a stronger defence can be given. Whatever the technical virtuosity it may permit, I do not believe that perfecting a theory of comparative adjectives is the most important end of philosophical inquiry (cf. Mackie, 1977). Rather, the most useful point of much philosophical logic is critical and normative. In this light, to talk of ellipsis is, as Sloman suggests, more a critical move than an attempt to elucidate what people have in mind. It says, 'If you want to say something determinately true or false, you must be understood as adding ....' Ellipsis can provide a way of understanding valid and invalid inferences more perspicuously; it can account for many of the nuances usually attributed to an unanalyzed context or shunted off into pragmatics; it can illuminate the ways ideology and unclarity persist (cf. my 1984b); and the varied examples we have glanced at should indicate the range over which it can make these sorts of contribution.

For these critical purposes we do not need the final truth, the full story. Indeed, its baroque complexity may well make it positively unhelpful in these areas. Aristotle's logic, or Euler's diagrams, may not capture any part of any natural language in its complexity; but one could hardly deny their contributions to clearer thought. (Nor, of course, can one deny that it is possible to use them to pervert and hinder thought.) I have elsewhere (1984a) advocated such a bricoleur approach to philosophical analysis generally, in which one uses what tools are to hand and able to do the job (as I have been using traditional grammatical categories in this discussion). Ellipsis seems to me a peculiarly simple and powerful tool to elucidate context dependencies, equivocations, and confusions of thought, whether or not it will form part of our final grand theory of meaning.

Whatever the motivations of philosophers of language, logicians, and especially informal logicians, are usually concerned with the implicit logic of expressions not for its own sake but rather as a means of exposing and correcting incoherence and invalidity. As a central part of the ordinary language philosopher's arsenal, ellipsis might too obviously have falsified that illusory neutrality some such philosophers aspired to (cf. Graham, 1977, ch. II), but its affinity for such critical uses should make it very welcome in the informal logician's camp where values are somewhat more conspicuous. I hope this survey of its uses, attempt to clear up some of its problems, and indication of a few of its ramifications, will inspire further work both on and with the notion, and also in assessing its pedagogical utility in the promotion of critical thinking.

\section{Notes}

[1] I cannot claim to have searched exhaustively for such an account, but 1 could try the patience of my readers with a long list of likely works in which such silence reigns. Thus, in the Encyclopedia of Philosophy (Edwards, 1967), the term 
appears neither in the general index nor in the catalogue of logical terminology; the Kneales do not treat of it, though they casually remark that 'statements of relative necessity or possibility are often made elliptically and may for this reason be misunderstood as statements of absolute necessity or possibility' (Kneale and Kneale, 1962, p. 93); Alston's (1964) introduction to the philosophy of language discusses various ways in which words may be vague but does not mention the indeterminacy of phrases or sentences due to ellipsis; and so one could go on.

[2] 'Cum subtractum verbum aliquod satis ex ceteris intelligitur' (1921. IX. iii. 58; trans. H.E. Butler).

[3] 'Vicit pudorem libido, timorem audacia, rationem amentia', a quotation given by Quintilian from Cicero's Pro Cluent. vi. 15. Translation by H.E. Butler.

[4] Some arguments go on and onhow would Jespersen react to Hudson's recent remark 'here what seems to act as both relative pronoun and antecedent-like a compressed version of that which' (1976, p. 135)? Hudson does not, I think, endorse quite this analysis, and his surrounding discussion is explicitly tentative, but it testifies to the attractiveness of Sweet's analysis.

[5] There they, and various other phenomena to be mentioned later, are usually handled by deletion rules, though such grammarians are much more aware of the frightening complexity of such rules when explicitly stated. For deletions in transformational grammar see, for instance, Akmajian and Heny (1975, esp. ch. 7), Allerton (1975), and Hudson (1976, esp. ch. 3.9). A wide-ranging discussion can be found in Matthews (1981).
[6] The third type of case, abbreviated phrases, is semantically motivated, but ellipsis here has usually been seen as part of a historical account of the genesis of new meanings for a word or phrase. The elided element is usually obvious and is often, but not always, marked by syntactic oddities (such as the clash of genders in the French example).

[7] What he does say is:

For a speaker to mean some System, he need not actively think about the System. Nor need he be able to say much about the System or even know what a System is. To say that he has a certain System in mind is only to say that he is inclined to accept certain kinds of reasons in support or criticism of his utterance, and to regard other kinds of reasons as irrelevant. If he is unable to do such things even in a rough-andready way, then the truth of what he says cannot be assessed, for there is no way to determine what, if anything, he means. (1972, p. 95)

[8] 'We are concerned not with relations between $A$ and $B$ in general but with relations within certain limits or in a certain 'field';..

a cause is always a cause within a field' (Anderson, 1938, p. 130). This notion has been used by Mackie in several places in discussions of causality and responsibility.

[9] I have altered the numbering of examples to fit this paper's sequence.

[10] One could of course treat unsophisticated talk about distance rather in the way I suggested for 'is married', i.e., put the everyday frame of reference into the meaning of the predicate. Descriptively the choice between these approaches is a matter of the best overall theory of the language and its speakers, but for critical 
purposes the elliptical analysis seems to me much the better.

\section{References}

Akmajian, A. \& Heny, F.W. An introduction to the principles of transformation syntax. Cambridge, Mass : : MIT Press, 1975

Allerton, D.J. Deletion and proform reduction. Journal of Linguistics, 1975, 11, 213-237.

Alston, W.P. Philosophy of language. Englewood Cliffs: Prentice-Hall, 1964.

Altham, J.E.J. The logic of plurality. London: Methuen, 1971.

Anderson, J. The problem of causality. In Studies in empirical philosophy. Sydney: Angus and Robertson, 1962 (orig. 1938).

Ayer, A.J. Probability and evidence. London: Macmillan, 1972.

Brandon, E.P. Hintikka on akolouthein. Phronesis, 1978, 23, 173-178.

Brandon, E.P. O reason not the need. Education for Development, 1980, 6, 18-25.

Brandon, E.P. Quantifiers and the pursuit of truth. Educational Philosophy \& Theory, 1982, 14, 50-58.

Brandon, E.P. The philosophy in philosophy of education. Teaching Philosophy, 1984, 1-15. (a)

Brandon, E.P. Ellipsis and ideology. Paper to be presented at the Conference on Thinking, Harvard University, Aug. 1984. (b)

Edwards, P. (Ed.) The encyclopedia of philosophy. New York: Crowell Collier and Macmillan, Inc., 1967.

Ennis, R.H. Identifying implicit assumptions. Synthese, 1982, 51, 61-86

Fowler, H.W. A dictionary of modern English usage. Revised by Sir Ernest Gowers. Oxford: Oxford University Press, 1983.

Graham, K. J.L. Austin: a critique of ordinary language philosophy. New Jersey: Humanities, 1977.

Hamblin, C.L. Fallacies. London: Methuen, 1970.

Hudson, R.A. Arguments for a nontransformational grammar. Chicago: University of Chicago Press, 1976.
Jespersen, O. The philosophy of grammar. London: George Allen \& Unwin, 1924

Johnson, R.H. \& Blair, J. A. The recent development of informal logic. In J.A. Blair \& R.H. Johnson (Eds.), Informal logic. Inverness, California: Edgepress, 1980.

Keynes, J.M. A treatise on probability. London: Macmillan, 1921.

Kneale, W. Probability and induction. Oxford: Clarendon Press, 1949.

Kneale, W. \& Kneale, M. The development of logic. Oxford: Clarendon Press, 1962.

Lausberg, H. Handbuch der literarischen Rhetorik. München: Max Hueber Verlag, 1960.

Mackie, J.L. Truth, probability, and paradox. Oxford: Clarendon Press, 1973

Mackie, J.L. Review of I. Hacking, Why does language matter to philosophy?. Philosophy, 1977, 52, 359-362.

Matthews, P.H. The adequacy of grammars. Aristotelian Society Supplementary Volume, 1970, 44, 175-190.

Matthews, P.H. Syntax. Cambridge: Cambridge University Press, 1981

Platts, M. Ways of meaning. London: Routledge, 1979.

Quintilian. The institutio oratoria of Quintilian, trans. H.E. Butler. London: Heinemann, 1921.

Sloman. A. 'Ought' and 'better'. Mind, 1970, 79, 385-394.

Swinburne, R. Space and time. London: Macmillan, 1968

Toulmin, S. Probability. In A. Flew (Ed.), Essays in conceptual analysis. London: Macmillan, 1956.

Ullmann, S. Semantics: an introduction to the science of meaning. Oxford: Basil Blackwell, 1962.

Wertheimer, R. The significance of sense. Ithaca: Cornell University Press, 1972.

Williams, C.J.F. What is truth? Cambridge: Cambridge University Press, 1976.

Professor E.P. Brandon, School of Education, University of the West Indies, Mona, Kingston 7, Jamaica 